\title{
Accurate Masses for Structure Confirmation
}

\author{
Michael L. Gross, Editor
}

A 11 members of this society appreciate that a time-honored use of high resolution mass spectrometry is the determination of exact masses so that elemental compositions of new compounds can be established. Our colleagues in synthetic, naturalproducts, and environmental chemistry count on mass spectrometrists to provide these measurements so that they can confirm their structural assignments of synthetic compounds or of unknowns isolated from biological or environmental samples. Key issies in this work are the accuracy and precision of the exact mass measurements, two issues that are often confused by consumers of mass spectrometric data.

An example is the recent requirement of the Journal of Organic Chemistry that the acceptable error limits are \pm 5 ppm for high resolution mass spectral data. Although the specification of \pm 5 ppm clearly refers to the agreement of the measured and expected exact masses, no consideration is given to the accuracy or the precision of the measuring device. Furthermore, although errors of greater than $5 \mathrm{ppm}$ may be adequate to allow distinctions between many possible compounds, it also may be insufficient, particularly for higher mass materials.

Discussion of this issue by the Committee on Measurements and Standards of the American Society for Mass Spectrometry (Professor Jack Henion, chair) was prompted by an inquiry by Dr. John Greaves of the University of California-Irvine. A subcommittee of Dr. Anne B. Giordani of Parke-Davis Pharmaceutical Research and Dr. Philip C. Price of Union Carbide then developed a policy statement, which has been reviewed by the whole committee as well as by Professor Richard Caprioli, editor-in-chief of Biomedical Mass Spectrometry, Professor Catherine C. Fenselau, associate editor of Analytical Chemistry, and myself. The statement has received the endorsement of The Board of Directors of the American Society for Mass Spectrometry.

I suggest the statement is worthy of your consideration and, therefore, I am publishing it as part of this editorial. I wish to acknowledge the efforts of Drs. Giordani and Price and all the others who assisted them with the development of this statement.

\section{The Use of High Resolution Mass Spectral Data for Structure Confirmation}

The acceptable uncertainty in a measurement by any analytical method must be evaluated as to whether it is adequate for the intended use of the data [1]. High resolution mass spectral data are often used to confirm identities of synthetic and natural products (see for example, "Guidelines for Authors," J. Org. Chem. 1993, 58, 7A-12A). The uncertainty in the exact mass measurement used for structure verification must be reported along with the result.

The uncertainty of exact mass measurement may be evaluated in any statistically valid fashion, for example, by determining the precision and accuracy of replicate measurements (see any analytical chemistry textbook, for example, D. A. Skoog and D. M. West, Analytical Chemistry, 3rd ed.; Philadelphia: Saunders College, 1980) or by evaluating the performance characteristics of the mass spectrometer used [2].

When the result of exact mass measurement is used for empirical formula confirmation, all candidates fitting the experimentally determined value and its reported uncertainty must be considered. Setting fixed acceptable error limits for exact mass measurement is not recommended, as the following illustrates: When valence rules and candidate compositions encompassing $C_{0-100}$, $\mathrm{H}_{3-74}, \mathrm{O}_{0-4}$, and $\mathrm{N}_{0-4}$ are considered at nominal parent mass 118, there are no candidate formulae closer together than $34 \mathrm{ppm}$. At nominal parent mass 500 , there are five compositions that have a neighboring candidate less than $5 \mathrm{ppm}$ away. Using $\mathrm{C}_{0-100}, \mathrm{H}_{25-110}, \mathrm{O}_{0-15}$, and $\mathrm{N}_{0-15}$ at mass 750.4 , there are 626 candidate formulae that have a neighboring possibility less than 5 ppm away. Thus, for a measurement at $m / z 118$, an error of only 34 ppm uniquely defines a particular formula. At $m / z$ 750, an error of $0.018 \mathrm{ppm}$ would be required to eliminate all extraneous possibilities.

\section{References}

1. Garfield, F. M. Quality Assurance Principles for Analytical Lahoratories; Association of Official Analytical Chemists: Arlington, VA.

2. Sack, T. M.; Lapp, R. L.; Gross, M. L.; Kimble, B. J. International Journal of Mass Spectrometry and Ion Processes 1984, 61, 191-213. 